Norris, C. E., Colman, A. M., \& Aleixo, P. A. (2003). Selective exposure to television programmes and advertising effectiveness. Applied Cognitive Psychology, 17, 593-606.

\title{
Selective Exposure to Television Programmes and Advertising Effectiveness
}

\author{
Claire E. Norris \\ De Montfort University, Leicester, UK \\ Andrew M. Colman \\ University of Leicester, UK \\ Paulo A. Aleixo \\ De Montfort University, Leicester, UK
}

\begin{abstract}
This study focused on the influence of selective exposure within an experiment designed to investigate context effects on advertising effectiveness. In a semi-natural viewing environment, 86 participants chose one of four television programmes to view. The programmes belonged to diverse genres: news and current affairs, light entertainment, sport, and action-adventure. Each programme was interrupted by two commercial breaks containing unfamiliar advertisements for familiar product types. Self-rated involvement, entertainment, and enjoyment of programmes correlated positively with subsequent measures of memory for and responses to the advertisements. The results support the hypothesis that the operation of selective exposure within an experimental situation may result in positive relationships between predictor variables and measures of advertisement effectiveness.
\end{abstract}

Four decades of research into context effects on cognitive processing of information have been characterised by disparate methods and inconsistent results. In research devoted to television advertising, some studies have produced evidence of a positive or facilitative relationship between viewer responses to programme contexts and advertisement effectiveness, while others have reported a negative or inverse relationship. Attempts to reconcile and explain these apparent contradictions have tended to focus on methodological issues. Colman, Grimes, and Wober (1989), Schumann and Thorson (1990), Thorson, Friestad, and Zhao (1987), and Lloyd and Clancy (1991) suggested that the inconsistencies may be attributed to the use of survey versus experimental methodologies. For example, Schumann and Thorson suggested that studies using survey methods have usually reported a positive relationship between programme-induced viewer involvement and/or viewer liking and memory for advertisements (e.g., Clancy \& Kweskin, 1971; Home Testing Institute, 1963; Leach, 1981; Priemer, 1983; Smith, 1956), whereas experimental studies have generally found a negative relationship (e.g., Bryant \& Comisky, 1978; Furnham, Gunter, \& Walsh, 1998; Kennedy, 1971; Norris \& Colman, 1992, 1993; Soldow \& Principe, 1981; Thorson \& Oberman, 1985; Thorson, Reeves, \& Schleuder, 1986; Thorson, Reeves, Schleuder, Lang, \& Rothschild, 1985).

In a wide-ranging review of the effects of programmes on attitudes to advertisements, Thorson, Friestad and Zhao (1987) suggested that the pattern of results was in some ways similar to the effects on memory for advertisements. Most survey studies have reported a positive relationship between programme impact and attitudes to advertisements (e.g., Home Testing Institute, 1963; Krugman, 1983; Smith, 1956; Twyman, 1974). However, experiments that have investigated context effects on attitudes to advertisements have yielded contradictory results. Some studies have found a positive relationship (e.g., Kennedy, 1971; Television Audience Assessment, 1984); others have found a negative relationship (e.g., 
Axelrod, 1963; Schwerin, 1958; Soldow \& Principe, 1981); and still others have found little effect on attitudes (e.g., Thorson \& Oberman, 1985).

Thorson, Friestad and Zhao (1987) suggested that the reason for these differences is that surveys and experiments are not measuring the same processes. In studies using survey methodologies, participants have the opportunity for selective exposure, by choosing to watch particular programmes rather than engage in another activity or switch channels. Consequently, high-impact programmes are likely to sustain audience attention, and viewers are therefore more likely to watch the advertisements and remember them. Experiments, on the other hand, force exposure upon viewers, so that even low-impact programmes receive sustained attention. Experimental participants are not free to choose what they watch. In experimental studies, differences in memory are therefore unlikely to be due to selective exposure. This hypothesis distinguishes between selection and processing and implies that surveys measure the effects of selective exposure, whereas experiments measure the effects of psychological processes, with exposure artificially held constant. As Schumann and Thorson (1990) suggested, an implication of this selective exposure hypothesis is that "any measure that taps the likelihood of watching programs will be positively related to memory and attitudes towards commercials" (p. 12).

In order to test this hypothesis, Thorson, Friestad and Zhao (1987) introduced selection into an experimental situation. Selective exposure was operationalised by creating a comfortable home-style environment, allowing participants to chat, watch television, get refreshments, or read. The only prohibited activity was switching channels. These researchers found that choosing to watch the programming segment immediately preceding the commercial break was significantly related to watching the advertisements and hence to recalling and recognising those advertisements later on. A similar relationship was found between selective exposure and attitudes to the advertisements, but no significant relationship emerged between selective exposure and buying intentions. According Thorson, Friestad, and Zhao, the results were consistent with those of the survey literature and were attributable to the operation of selective exposure.

Lloyd and Clancy (1991) provided some support for the selective exposure hypothesis without testing it directly. They hypothesised that the inconsistent results within the context effects literature resulted from two main factors: first, the fact that surveys were carried out in home environments, and second, that previous research had used single unsophisticated measures of programme involvement. These researchers therefore carried out an experimental study in which participants were tested in a simulated living-room atmosphere, and they found that memory and buying intentions were higher for advertisements embedded in programmes that were rated highly on a multidimensional summated-rating scale designed to measure viewer involvement.

Further support was provided by RBL (cited in Johnson, 1992) and Television Audience Assessment (1984), using an experimental methodology but testing participants in an informal relaxed environment in which a degree of selective exposure was allowed to operate. Both studies reported a positive effect of high-impact programmes on cognitive processing of advertisements.

However, in all of the selective exposure studies reviewed above, participants were not permitted to choose the programmes that they watched. This is an important omission, because the choice of programme is a fundamental aspect of selective exposure as it occurs in the home environment, and it is a key factor differentiating survey research from experimental research. Audience appreciation may be highest among respondents who actively choose to watch a programme, and this may help to explain some of the anomalies in the literature. 
Furthermore, the predictor variables used in experiments and surveys are various and inconsistent, and this has clouded and confused empirical evidence on the selective exposure hypothesis and the survey versus experiment dichotomy. It is not known whether all predictor variables would be similarly affected by selective exposure, and it has been noted that it is unwise to use such variables interchangeably (Norris \& Colman, 1993, 1994a, 1994b). However, the phenomenon of selective exposure does suggest the possible importance of testing context effects under more naturalistic conditions. The aim of the experiment reported in this article was therefore to test the proposition of Schumann and Thorson (1990) that any measure which taps the likelihood of watching programmes (selective exposure) will be positively related to memory for the associated advertisements, and will also be positively related to attitudes to the accompanying advertisements.

Viewer involvement was used as a major predictor variable, because it is one of the most robust predictors in the context effects literature. When measured in experimental settings with no opportunity for selective exposure, involvement has often been found to be negatively related to advertisement effectiveness (Bryant \& Comisky, 1978; Colman Grimes, \& Wober, 1989; Norris \& Colman, 1992, 1993; Park \& McClung, 1986; Soldow \& Principe, 1981; Thorson \& Reeves, 1986). If the selective exposure hypothesis is correct, then the existence of free choice within an experimental situation should create positive relationships between viewer involvement and measures of advertisement effectiveness. The entertainment and enjoyment properties of programme contexts were also included as predictor variables, because they are also likely to influence viewing behaviour under conditions of selective exposure. Empirical definitions of involvement, entertainment and enjoyment, as used in this study, were derived from a large-scale cluster analysis of a large pool of candidate items, including those that have been used in previous published work (Norris \& Colman, 1994b).

Participants, selected from members of the general public, chose to watch one of four television programmes in a natural viewing environment. They were allowed to chat, leave the room, read magazines, take refreshments, and do almost anything that they might do at home. Unlike previous experiments in which selective exposure was free to operate, participants were allowed to choose the specific programmes they wished to watch, on the basis of brief descriptions similar to those found in TV listings magazines, although they were not permitted to switch channels after making their choices. Each programme was interrupted by two identical commercial breaks containing unfamiliar advertisements for familiar product types. Participants then responded to a series of questionnaires designed to measure their perceptions of the programming materials and their memory for and responses to the advertisements.

\section{Method}

Participants

Participants were 49 women and 37 men selected from a database of volunteers drawn from the general population of a large city in the East Midlands of England. Information about the participants' ages was collected in six age bands (10-19, 20-29, 30-39, 40-49, 50$59,60+$ ). The modal age band of the sample was 20-29.

Assignment to the four treatment conditions used in the experiment was based on selective exposure, with participants choosing freely which of four programmes they wished to watch. It is therefore useful to check whether the resulting four groups were broadly similar according to demographic variables. The percentages of women in the four treatment conditions were 53\%, 61\%, 69\%, and 50\% respectively, and the gender distribution across treatment conditions turned out to be non-significant: $\chi^{2}(3)=1.62, p>.05$. To compare the age distribution across treatment conditions, participants were grouped into broader age bands (under 30, 30 to 49, 50, and over) to eliminate low expected frequencies and thus to 
enable chi-square analysis to be performed. For participants in the youngest group, the percentages across treatment conditions were 20\%, 30\%, 11\%, and 39\% respectively, and for the oldest age group the percentages were $27 \%, 27 \%, 27 \%$, and $18 \%$ respectively. The age distribution across treatment conditions turned out to be non-significant: $\chi^{2}(6)=6.80, p>$ .05. To compare educational level across conditions, participants were grouped, to eliminate low expected frequencies, into those with up to two years of formal education since their 16th birthdays and those with more than two years. The percentages of the less educated participants across conditions were $16 \%, 57 \%, 36 \%$, and $69 \%$ respectively, $\chi^{2}(3)=13.96, p$ $<.01$. This significant association was due largely to the unusually small percentage of less educated participants in the first condition. Partly in the light of this, education was included as a predictor variable in a multiple regression analysis described later in the article.

\section{Design and Materials}

This study investigated the effect of selective exposure in an experiment designed to measure context effects. Selective exposure was operationalised by giving participants the choice of watching one of four programmes. Viewing took place in a comfortable home-style setting, and participants were encouraged to bring friends, relatives, and colleagues to the experiment. Participants were given refreshments, allowed to chat to other participants, leave the room, read a magazine, or just watch the programme.

Programmes. The programmes and advertisements used in the experiment were taken from the South African channel TV1. This enabled the use of English-language material that the participants were unlikely to have seen before, thus controlling for prior exposure. The programmes chosen covered the following four sharply contrasting genres.

Condition 1: News and current affairs: The Six O' Clock News (excerpts of 8 minutes 6 seconds, and 13 minutes and 32 seconds, from two separate bulletins), followed by Network (23 minutes and 57 seconds); total length 45 minutes and 35 seconds, excluding advertisements, covering domestic and international news and weather. This video was chosen for viewing by 19 participants (10 females and 9 males).

Condition 2: Light entertainment: You Can't Take it with You (21 minutes and 19 seconds), followed by No Jacket Required (24 minutes and 3 seconds); total length 45 minutes and 22 seconds, excluding advertisements. The first of these programmes was an American situation comedy that had not been screened in Britain, and No Jacket Required was a light music programme. This video attracted 28 viewers (18 females and 10 males).

Condition 3: Sport: Top Sport (excerpts of 8 minutes and 56 seconds, 14 minutes and 14 seconds, and 22 minutes and 11 seconds from two separate broadcasts); total length 45 minutes and 21 seconds, excluding advertisements. This sports programme was chosen for viewing by 13 participants (4 males and 9 females).

Condition 4: Action-adventure: Jake and the Fat Man (45 minutes and 46 seconds, excluding advertisements). This was an episode of a typical American detective serial, which had not been screened in Britain. It was chosen for viewing by 26 participants (13 males and 13 females). The four programmes used in the experiment were found to differ significantly on all three predictor variables used in the experiment: viewer involvement: $F(3,82)=9.31, p$ $<.001$; entertainment: $F(3,82)=5.45, p<.01$; and enjoyment: $F(3,82)=5.90, p<.01)$.

Advertisements. Each programme was interrupted by two commercial breaks, each containing three advertisements. The advertisements, recorded off air from South Africa's channel TV1, were for a wide range of familiar product types, with brand names unlikely to have been encountered in Britain. The first set (2 minutes and 27 seconds) contained advertisements for Close-Up toothpaste, Jik Colours washing powder and Ohlssons lager, in that order. The second set (1 minute and 46 seconds) contained advertisements for Avbob 
Life assurance, Silk-e toilet soap, and Jordan shoes, in that order. The first commercial break was edited into each of the four programme tapes 8-9 minutes after the beginning of the programme, and the second 23-25 minutes after the beginning.

Questionnaires. Several questionnaires were used to measure the participants' perceptions of the programmes and advertisements and their recall and recognition of the advertisements. After supplying details of their sex, age, and education, participants were asked to respond to the following seven questionnaires.

Programme ratings. Participants responded to nineteen counterbalanced seven-point scales, designed to measure participants' ratings of the entertainment, enjoyment, and involvement properties of the programmes. These consisted of bipolar adjective pairs, such as relaxing - not relaxing, separated by standard semantic-differential-type seven-point rating scales, with instructions specifying that "the closer you place your tick to one of the words, the more you agree with it”. These nineteen scales comprised the empirical definitions of involvement, entertainment, and enjoyment derived from a full-scale cluster analysis of a much larger number of candidate items, including those used in previous research (Norris \& Colman, 1993, 1994a, 1994b, 1996; Norris, Colman, \& Aleixo, 2001). These ratings were aggregated to form three scores, corresponding to the rated entertainment, enjoyment, and involvement properties of the programmes. Cronbach's alpha coefficient of reliability was .79 for the entertainment scale, .77 for the enjoyment scale, and .88 for the involvement scale (Nunnaly, 1978, has suggested that alpha coefficients of .70 and above are acceptable).

Measures of recall and recognition. Participants' recall and recognition of the six advertisements were measured with the following five scales adapted from those used in previous context research (Bryant \& Comisky, 1978; Colman, Grimes, \& Wober, 1989; Heflin \& Haygood, 1985; Kennedy, 1971; Murphy, Cunningham, \& Wilcox, 1979; Norris \& Colman, 1992, 1993, 1994a, 1996; Norris, Colman, \& Aleixo, 2001; Schumann, 1986; Soldow \& Principe, 1981; Thorson, Friestad, \& Zhao, 1987). (a) Free recall of advertisements: Participants were asked to write down as much as they could remember about the six advertisements including brand name, product, and advertisement details. (b) Recognition of product types: Participants were asked to recognise the six product types from among a total of 48 advertised product types presented to them. The six target product types were randomly inserted in a list with 42 others. (c) Cued recall of brand names: The six product types relating to the advertisements previously viewed were presented, and the participants were asked to recall the corresponding brand names. (d) Recognition of brand names: Each brand name was placed beneath the relevant product type, randomly mixed with five other possible brand names. The respondent's task was to circle the appropriate brand name. To control for prior exposure, all brand names were for products unavailable in Britain. (e) Recognition of advertisements: Participants were asked to select photographs of the six target advertisements from 12 other photographs of real advertisements also shown on South African television. The eighteen photographs, each measuring 15 x 20 centimetres, were taken directly from television images. To avoid ceiling effects and ensure comparability, they were taken between the 25th and 35th freeze-frame of each advertisement, or the nearest frame which did not reveal the product or brand name.

Advertisement ratings. Brief summaries of the target advertisements were provided, and participants were asked to rate them on a series of seven-point rating scales, measuring attitudes to the advertisements, attitudes to the brands, intention to buy the products, and selfestimations of memory for the advertisements (metamemory). These ratings were based on similar items used in previous research (Colman, Grimes, \& Wober, 1989; Homer, 1990; MacKenzie \& Lutz, 1989; MacKenzie, Lutz, \& Belch, 1986; Norris \& Colman, 1993, 1994a, 1996; Norris, Colman, \& Aleixo, 2001; Yi, 1990). 


\section{Procedure}

Participants were tested in groups of one to five. They were told that the research related to psychological aspects of viewing, and that they would be asked to watch a programming segment and then fill in a questionnaire. They were given a choice of programmes to watch from a typed sheet containing descriptions in the style of TV listings magazines. Once the participants had indicated a choice of programme, they were taken to one of four viewing rooms, depending on the programme chosen, and informed that the programming segments were taken from a foreign television channel but that the language was English. They were encouraged to relax, to pretend they were at home, and do whatever they would normally do when watching television. For example, they were told they could read a magazine, talk, simply watch, or leave the room. In the event, only one participant chose to leave the room, to visit the toilet. No mention was made of the advertisements. The programme was switched on and the experimenter left the room.

When the tape had ended, the participants were given the questionnaires in the order in which they were described above. They were not allowed to backtrack in the booklet to change or supplement their answers on the basis of information given in later questionnaires. Two minutes were allowed for each questionnaire, apart from the one concerned with recall of advertisements, products types, and brand names, for which six minutes were allowed, and the advertisement ratings were untimed. If participants could not remember a detail clearly, they were asked to guess. After filling in the questionnaires, they were debriefed and thanked for their participation.

Scoring of questionnaires. The seven-point rating scales were each scored from zero (low) to six (high). The scoring of the recognition measures was straightforward: in each case one point was awarded for a correct choice and zero for an incorrect choice. The recall questionnaires yielded four scores: free recall of advertisements, product types, and brand names, and cued recall of brand names. Free recall of advertisements was scored on the basis of 18 salient points for each advertisement, drawn up in advance, covering virtually all details mentioned by the participants. Recognition of product types was scored on a three-point scale for each advertisement: two points for a response that was perfectly or virtually correct; one point for substantially but imperfectly correct recall (e.g. alcoholic drink instead of lager); and zero for an incorrect response. Cued recall of brand names and recognition of brand names were both scored on a five-point scale for each advertisement: four points for a response that was perfectly or virtually correct (Ohlssons or Ohlson instead of Ohlssons), three points for an almost correct response with a small mistake or omission (Orsons), two points for recognisable elements of the word's sound or appearance without the answer being classifiable as almost correct (Johnsons instead of Jordan) and one mark for the correct initial letter or number of syllables with no other recognisable element of the word's sound or appearance ( $\mathrm{O}_{\text {_ }}$ instead of Ohlssons). No marks were awarded if the word was completely incorrect or had the correct initial letter corresponding to that of a common British brand name. Recognition of advertisements was scored from zero to six indicating the number of advertisements correctly identified.

The scoring of the free recall and cued recall questionnaires was done by two independent judges. When there was a discrepancy, the mean of the two separate scores was taken. As a check on the reliability of the scoring procedures, correlations between judges' scores were calculated. The correlations were found to be $r=.98(p<.001)$ for free recall and $r=.98(p<$ .001) for cued recall.

The questionnaire measuring perceptions of the programmes produced three scores corresponding to the rated entertainment, enjoyment, and involvement properties of the 
programmes. Scores from the recall questionnaires (a) and (c) (free recall and cued recall) were combined to form a global recall score. Scores from the recognition questionnaires (b), (d), and (e) (recognition of products, brand names, and advertisements) were combined to form a global recognition score. Scores from all the recall and recognition questionnaires formed a global memory score for each participant.

\section{Results}

Programme Ratings and Memory for Advertisements

Memory was generally better for the advertisements in the first commercial break than the second. Differences were significant on paired-samples $t$ tests for both advertisement recall, $M_{1}=40.01, M_{2}=24.50, t(85)=2.88, p<.01$, and advertisement recognition, $M_{1}=$ 2.03, $M_{2}=1.63, t(85)=3.78, p<.001$.

Product-moment correlations between programme ratings and memory scores were analysed separately for the three advertisements in the first commercial break and the three advertisements in the second advertising break. The results are shown in Table 1.

Table 1

Correlations Between Programme Ratings and Memory for Advertisements in First and Second Commercial Breaks

Recall Recognition Memory

1 st ad break

\begin{tabular}{clll} 
Entertainment & .12 & -.08 & .09 \\
$\quad$ Enjoyment & .12 & .05 & .11 \\
Involvement & $.27^{*}$ & .02 & $.25^{*}$ \\
2nd ad break & & & \\
& .01 & .08 & .02 \\
Entertainment & & & \\
$\quad$ Enjoyment & .04 & $.23^{*}$ & .09 \\
Involvement & .08 & -.04 & .05 \\
\hline
\end{tabular}

$* p<.05$

Nearly all of the correlations were positive, but most were non-significant ( $p>.05)$. Just three of the correlations were significant. Recall of advertisements in the first commercial break correlated positively and significantly with involvement. Recognition of the advertisements in the second commercial break correlated positively and significantly with enjoyment. Global memory in the first commercial break correlated positively and significantly with involvement. All three effect sizes were small to medium according to Cohen’s (1992) criterion. 
Table 2

Recall and Recognition Scores Across Conditions (Programmes)

\begin{tabular}{lrrrr}
\hline & \multicolumn{5}{c}{ Condition (Programme) } \\
\cline { 2 - 5 } & \multicolumn{1}{c}{2} & \multicolumn{1}{c}{3} & \multicolumn{1}{c}{4} \\
\hline & & & & \\
Free recall of ads & 121.0 & 42.0 & 108.0 & 76.0 \\
Product recognition & 4.2 & 4.2 & 3.7 & 5.0 \\
Brand cued recall & 25.0 & 18.0 & 7.0 & 36.0 \\
Brand name recognition & 3.5 & 4.1 & 3.7 & 4.7 \\
Recognition of ads & 3.7 & 3.6 & 3.1 & 4.0 \\
\hline
\end{tabular}

Recall and recognition scores across conditions are shown in Table 2. No significant differences were found between the four treatment conditions in recall, $F(3,82)=1.08$, recognition, $F(3,82)=2.34$, or global memory, $F(3,82)=1.18, p>.05$ in each case. In order to check whether the variable numbers of participants present at different testing sessions affected recall, recognition, or global memory scores, analyses of covariance were performed, using the numbers of participants at different testing sessions as a covariate, and the results were essentially the same. Previous research has found programme context effects on recall and recognition of embedded advertisements (e.g., Colman, Grimes, \& Wober, 1989; Furnham, Gunter, \& Walsh, 1998; Kennedy, 1971; Murphy, Cunningham, \& Wilcox, 1979; Norris, Colman, \& Aleixo, 2001; Television Audience Assessment, 1984), but the experiment reported in this article was not designed to study such effects, and the programmes were not selected with the objective of producing between-programme memory effects. This experiment was concerned with within-programme selective exposure effects.

\section{Attitudes, Buying Intentions, and Recall of Advertisements}

Self-rated attitudes to advertisements correlated positively and significantly with recall ( $r$ $=.28)$ and recognition $(r=.30)$ of advertisements $(p<.05$ in both cases). Self-rated attitudes towards brands correlated positively and even more significantly with recall $(r=.37)$ and recognition ( $r=.35$ ) of advertisements ( $p<.0005$ in both cases). Finally, self-rated rated intentions to buy the advertised products correlated positively and highly significantly with recall of advertisements $(r=.34)$ and recognition $(r=.36)$ of advertisements $(p<.005$ in both cases). These correlations between advertisement ratings and memory for advertisements are stronger and more highly significant than the correlations between programme ratings and memory for advertisements shown in Table 1.

\section{Ratings of Programmes and Advertisements}

The majority of correlations between programme and advertisement ratings were positive and highly significant, as shown in Table 3. Attitude to the advertisements, attitude to the brands, and intention to buy the products correlated positively and significantly with participants' ratings of the programmes as entertaining, enjoyable, and involving, with correlations typically in the medium to large range for entertainment and small to medium for involvement). 
Table 3

Correlations Between Programme Ratings and Responses to Advertisements

Entertainment Enjoyment Involvement

Attitude to ad

$\begin{array}{llll}\text { All ads } & .46^{* * *} & .41^{* * *} & .27^{*} \\ \text { 1st ad break } & .37^{* * *} & .36^{* * *} & .26^{*} \\ \text { 2nd ad break } & .42^{* * *} & .34^{* *} & .20\end{array}$

Attitude to

brand

\begin{tabular}{llll} 
All ads & $.41^{* * *}$ & $.30^{* *}$ & $.29^{* *}$ \\
1st ad break & $.36^{* * *}$ & $.28^{* *}$ & $.27^{*}$ \\
2nd ad break & $.33^{* *}$ & $.23^{*}$ & $.23^{*}$ \\
ntention to buy & & & \\
All ads & $.33^{* *}$ & $.37^{* * *}$ & $.26^{*}$ \\
1st ad break & .20 & $.28^{* *}$ & .17 \\
2nd ad break & $.34^{* *}$ & $.34^{* *}$ & $.26^{*}$ \\
\hline
\end{tabular}

${ }^{*} p<.05 .{ }^{*} p<.01 .{ }^{* * *} p<.001$.

\section{Multiple Regression: Recall and Recognition}

Stepwise multiple regression analyses were performed to determine the influence on each of the five major recall and recognition measures of the following predictor variables: sex, age, education, mean attitude to the advertisements viewed (adatt), mean attitude to the brands (brandatt), mean intention to buy the advertised products (intbuy), and ratings of programmes (entertainment, enjoyment, involvement). The significant regression coefficients of the standardised regression equations, using a criterion of $p<.05$, together with coefficients of multiple determination and model significance levels, were as follows:

Free recall of ads $=.46$ brandatt +.29 education, $R^{2}=.23, p<.001$.

Recognition of product types $=-.34$ age +.32 brandatt, $R^{2}=.24, p<.001$.

Cued recall of brand names $=.31$ brandatt +.22 education -.22 age, $R^{2}=.19, p<.005$.

Recognition of brand names $=.26$ intbuy -.22 age, $R^{2}=.14, p<.005$.

Recognition of advertisements $=-.41$ age +.21 brandatt, $R^{2}=.23, p<.001$.

Gender and Age Differences in Recall and Recognition

The free-choice methodology of the experiment precluded control of gender and age variables. The effects of these variables are nevertheless worth investigating. The scores of male and female participants were compared separately on each of the five measures of recall and recognition. The results are displayed in Table 4. Although the mean score on the measure of free recall of advertisements was higher for women than men, this difference was not significant with a two-tailed independent-groups $t$ test. On other measures, the scores of men and women were similar, and none of the differences approached significance. 
Table 4

Gender Differences in Recall and Recognition

\begin{tabular}{lrrrrr}
\hline & \multicolumn{2}{c}{ Gender } & & \\
\cline { 2 - 3 } & \multicolumn{2}{c}{ Male } & Female & & \\
\cline { 2 - 3 } \cline { 5 - 6 } Memory measure & & & & & \\
\cline { 1 - 2 } Ad free recall & 64.81 & 90.82 & & 1.10 & Sig. \\
Product recognition & 4.32 & 4.37 & & 0.12 & $n s$ \\
Brand cued recall & 24.08 & 22.10 & & 0.21 & $n s$ \\
Brand name & 4.19 & 4.04 & & 0.39 & $n s$ \\
recognition & & & & \\
Ad recognition & 3.59 & 3.71 & & 0.42 & $n s$ \\
\hline
\end{tabular}

Similar comparisons were made between the scores of participants in each of the six age bands. The results are shown in Table 5. Using one-way Analysis of Variance, no significant age differences emerged on free recall of advertisements or cued recall of brand names, but significant age differences emerged on the other measures. First, the age groups differed significantly on recognition of product types, and a post-hoc Tukey-HSD test revealed that the oldest group (60 years and over) scored significantly lower, on average, than members of all other age groups, and that the two oldest groups, together with the 30-39 age group, scored significantly lower than the two youngest groups (under 30 years) and the 40-49 age group. Second, on recognition of brand names, the overall $F$ ratio was significant, and a Tukey-HSD test showed that participants over 60 years scored significantly lower than participants in all other age bands, and that the 40-49 age group scored significantly higher than all other age bands. Finally, on recognition of advertisements, the oldest age group (over 60 ) scored significantly lower than all other age groups, and the two oldest age groups (50 and over), together with participants in the 30-39 age group, scored significantly lower than all other age groups, on average.

Table 5

Age Differences in Recall and Recognition

\begin{tabular}{|c|c|c|c|c|c|c|c|c|}
\hline \multirow[b]{2}{*}{ Memory measure } & \multicolumn{6}{|c|}{ Age group } & \multirow[b]{2}{*}{$F(5,80)$} & \multirow[b]{2}{*}{$p$} \\
\hline & 1 & 2 & 3 & 4 & 5 & 6 & & \\
\hline Ad free recall & 42.71 & 121.03 & 30.93 & 128.80 & 70.79 & 65.00 & 2.22 & $>.05$ \\
\hline Product recognition & 4.64 & 4.90 & 4.27 & 5.20 & 3.64 & 2.63 & 4.25 & $<.002$ \\
\hline Brand cued recall & 17.71 & 42.00 & 10.60 & 7.20 & 17.07 & 4.00 & 2.07 & $>.05$ \\
\hline Brand name recognition & 3.93 & 4.83 & 3.80 & 5.60 & 3.29 & 2.75 & 4.10 & $<.002$ \\
\hline Ad recognition & 4.07 & 4.27 & 3.27 & 4.00 & 3.00 & 2.38 & 5.20 & $<.001$ \\
\hline
\end{tabular}

\section{Discussion}

The results from this experiment tend to support the selective exposure hypothesis (Schumann \& Thorson, 1990; Thorson, Friestad, \& Zhao, 1987). The most striking aspect of the findings is the clear, positive relationship between certain predictor variables on the one hand and certain measures of memory for advertisements and ratings of advertisements on the other. 
The majority of the programme-induced involvement, entertainment, and enjoyment scores correlated positively with recall, recognition, and global memory scores for the advertisements. Three correlations reached significance. Involvement was positively and significantly correlated with recall and memory for the advertisements in the first commercial break, and enjoyment with recognition of advertisements in the second commercial break. The more the participants rated the programmes as involving, the better they recalled the advertisements from the first commercial break, and the more they rated the programmes as enjoyable, the more they recognised advertisements from the second commercial break. A partial and speculative explanation for this pattern of results rests on an assumption that involvement increases the depth of semantic and conceptual processing (Craik \& Lockhart, 1972). According to standard interpretations of levels of processing, deeper processing tends to produce more enduring memories but demands greater attention and effort, and the effects on memory may be most evident in free recall, because it is more cognitively demanding than recognition memory. In the experiment, viewers who were deeply absorbed in programmes may have processed the programme information and accompanying advertisements relatively deeply, resulting in superior subsequent recall of material from the first commercial break. If, in addition, enjoyment is associated with a shallower level of processing than involvement, then it may facilitate relatively short-lived memories that appear in less cognitively demanding recognition measures, and this might explain why it was associated with superior recognition of more recent material from the second commercial break.

More and stronger relationships were found between advertisement and programme ratings. Attitude to the advertisement, attitude to the advertised brands, and buying intentions correlated positively and significantly with rated entertainment, enjoyment, and involvement properties of programmes, and also with recall and recognition of the advertisements. The more participants found the programmes entertaining, enjoyable, and involving, the more favourably they rated the advertisements and the higher they rated their likelihood of buying the products.

The positive relationship between programme ratings on the one hand and memory and advertisement ratings on the other is similar to the findings reported in several studies using survey methodologies in which selective exposure was free to operate (Barclay, Doub, \& McMurtrey, 1965; Clancy \& Kweskin, 1971; Home Testing Institute, 1965; Krugman, 1983; Leach, 1981; Priemer, 1983; Smith, 1956; Twyman, 1974). But these positive results are in sharp contrast to the negative results observed in experimental research without selective exposure (Bryant \& Comisky, 1978; Kennedy, 1971; Soldow \& Principe, 1981; Television Audience Assessment, 1984; Thorson \& Oberman, 1985; Thorson \& Reeves, 1986; Thorson, Reeves, \& Schleuder, 1985). In particular, the positive relationship between viewer involvement and memory scores contrasts sharply with the results of experimental studies that have investigated this relationship and reported a significant negative or inverse relationship (Bryant \& Comisky, 1978; Norris \& Colman, 1993; Park \& McClung, 1986; Soldow \& Principe, 1981; Thorson \& Reeves, 1986).

The results of the experiment reported in this article replicate those of previous experiments incorporating selective exposure, in which participants were not free to choose the programmes that they watched (Lloyd \& Clancy, 1991; RBL, cited in Johnson, 1992; Television Audience Assessment, 1984; Thorson, Friestad, \& Zhao, 1987). This provides additional support for the selective exposure hypothesis (Schumann \& Thorson, 1987; Thorson, Friestad, \& Zhao, 1987). However, unlike Thorson, Friestad, and Zhao's research, this experiment also found evidence of significant positive relationships between programmeinduced involvement, entertainment, and enjoyment and participants' stated purchasing intentions. 
No significant gender differences were found on measures of recall and recognition of advertisements, but some differences were found between age groups. The most robust findings regarding age differences were that older participants, especially those aged 60 years and over, scored significantly lower than younger participants on recognition of product types, recognition of brand names, and recognition of advertisements. This is consistent with a well-established phenomenon of memory decline in later life (Burke \& Light, 1981; Craik, 1977; Poon, 1985). A multiple regression analysis revealed four variables that significantly influenced separate recall and recognition scores. First, in line with findings already discussed, age was negatively predictive of all recall and recognition scores except free recall of advertisements. Second, attitudes to brands were positively predictive of all recall and recognition scores except recognition of brand names. This is hardly surprising that participants remembered advertisements better when they held favourable attitudes towards the advertised brands. Third, education was positively predictive of free recall of advertisements and cued recall of brand names, perhaps because of positive effects of education on certain forms of memory. Last, intention to buy the advertised products was positively predictive of recognition of brand names, presumably because people are more likely to remember information when they perceive it to have practical utility for them.

It is noteworthy that involvement, entertainment, and enjoyment all produced similar relationships to memory scores and advertisement ratings, suggesting that the three predictor variables are similarly affected by selective exposure. However, in previous research without selective exposure, Norris and Colman $(1993,1994 a)$ found that the effects of these variables were quite different from one another. Further studies are therefore needed to clarify the complex interactions between different predictor variables and selective exposure.

The results of the experiment reported in this article need to be interpreted with caution. Although correlations between predictor variables and attitudes to advertisements were positive and significant, many of the correlations between the predictor variables and memory scores were non-significant. One possible explanation for the non-significant results may be the limited manipulation of selective exposure. Although there was an opportunity to select the programmes, the initial selection was once and for all, and participants were unable to change channels later on. Thus, although selective exposure was operationalised to a fuller extent than in previous studies, viewing conditions were nevertheless somewhat artificial. One of the effects was to limit selective exposure, and this may have been attenuated the relationships between predictor variables and memory scores.

Despite this, the positive relationships between predictor variables on the one hand and advertisement ratings (and some memory scores) on the other provide support for the selective exposure hypothesis. Selective exposure within an experimental situation appears to generate positive relationships between predictor variables and advertisement effectiveness, particularly for attitudes to the advertisements.

\section{References}

Axelrod, J. N. (1963). Induced moods and attitudes toward products. Journal of Advertising Research, 3(2), 19-24.

Barclay, W. D., Doub, R. M., \& McMurtrey, L. T. (1965). Recall of TV commercials by time and program slot. Journal of Advertising Research, 5(2), 41-47.

Bryant, J., \& Comisky, P. W. (1978). The effect of positioning a message within differentially cognitively involving portions of a television segment on recall of the message. Human Communication Research, 5(1), 63-75.

Burke, D. M., \& Light L. L. (1981). Memory and aging: The role of retrieval processes. 
Psychological Bulletin, 90, 513-546.

Clancy, K. J., \& Kweskin, D. M. (1971). TV commercial recall correlates. Journal of Advertising Research, 2, 18-20.

Cohen, J. (1992). A power primer. Psychological Bulletin, 112, 155-159.

Colman, A. M., Grimes J. E., \& Wober, M. (1989). Effects programme context on recall and recognition of television advertisements. Unpublished Report to the Independent Broadcasting Authority, London.

Craik, F. I. M. (1977). Age differences in human memory. In J. E Birren \& K. W. Schaie (Eds.), Handbook of the psychology of aging (pp. 384-420). New York: Van Nostrand Reinhold.

Craik, F. I. M., \& Lockhart, R. S. (1972). Levels of processing: A framework for memory research. Journal of Verbal Learning and Verbal Behavior, 11, 671-684.

Furnham, A., Gunter, B., \& Walsh, D. (1998). Effects of programme context on memory for humorous television commercials. Applied Cognitive Psychology, 12, 555-567.

Greenwald, A. G., \& Leavitt, C. (1984). Audience involvement in advertising: Four levels. Journal of Consumer Research, 11, 581-592.

Heflin, D. T. A., \& Haygood, R. C. (1985). Effects of scheduling on retention of advertising messages. Journal of Advertising, 14(2), 41-47, 64.

Homer, P. M. (1990). The mediating role of attitude toward the ad: Some additional evidence. Journal of Marketing Research, 27(1), 78-86.

Home Testing Institute, Inc. (1963). Must reading about HTI and TVQ. In-House Report, No. 22.

Johnson, H. (1992, January 17). Attention seekers. Media Week, 14-15.

Kennedy, J. R. (1971). How program environment affects TV commercials. Journal of Advertising Research, 11(1), 33-38.

Krugman, H. E. (1983). Television program interest and commercial interruption: Are commercials on interesting programs less effective? Journal of Advertising Research, 23(1), 21-23.

Leach, D. C. (1981, July 13). Should ads be tested? Advertising Age, 47-48.

Lloyd, D. W., \& Clancy K. J. (1991). CPMs versus CPMIs: Implications for media planning. Journal of Advertising Research, 31(4), 34-44.

MacKenzie, S. B., \& Lutz, R. J. (1989). An empirical examination of the structural antecedents of attitude toward the ad in and advertising pretesting context. Journal of Marketing, 53, 48-65.

MacKenzie, S. B., Lutz, R. J., \& Belch, G. E. (1986). The role of attitude toward the ad as a mediator of advertising effectiveness: A test of competing explanations. Journal of Marketing Research, 23, 130-143.

Murphy, J. H., Cunningham, I. C. M., \& Wilcox, G. B. (1979). The impact of program environment on recall of humorous television commercials. Journal of Advertising, 8, $17-21$.

Norris, C. E., \& Colman, A. M. (1992). Context effects on recall and recognition of magazine advertisements. Journal of Advertising, 21(3), 1-10.

Norris, C. E., \& Colman, A. M. (1993). Context effects on memory for television advertisements. Social Behaviour and Personality, 21(4), 279-296.

Norris, C. E., \& Colman, A. M. (1994a). Effects of entertainment and enjoyment of television programmes on perception and memory for advertisements. Social Behaviour and Personality, 22, 365-376.

Norris, C. E., \& Colman, A. M. (1994b). Putting ads in context: How television programmes affect viewers' reactions to ads. Admap, 29(1), 39-42. 
Norris, C. E., \& Colman, A. M. (1996). Context effects of radio programming on cognitive processing of embedded advertisements. Applied Cognitive Psychology, 10, 473-486.

Norris, C. E., Colman, A. M., \& Aleixo, P. A. (2001). Context effects of cognitively involving, entertaining and enjoyable television programmes on two types of advertisements. Social Psychological Review, 3(1), 3-24.

Nunnaly, J. (1978). Psychometric theory. New York: McGraw-Hill.

Park, C. W., \& McClung, G. W. (1986). The effect of TV program involvement on involvement with commercials. Advances in Consumer Research, 13, 544-548.

Pavelchak, M. A., Antil, J. H., \& Munch, J. M. (1988). The Super Bowl: An investigation into the relationship among program context, emotional experience, and ad recall. Journal of Consumer Research, 15(3), 360-367.

Poon, L. W. (1985). Differences in human memory with aging: Nature, causes, and clinical implications. In J. E Birren \& K. W. Schaie (Eds), Handbook of the psychology of aging (2nd ed., pp. 427-462). New York: Van Nostrand Reinhold.

Priemer, A. B. (1983, February). The use of qualitative evaluation: Problems, pitfalls and potentials. Paper presented at the National Advertisers' National Association Television Workshop, New York.

Schumann, D. W. (1986). Program impact on attitude toward TV commercials. In J. Seagert (Ed.), Proceedings of the division of consumer psychology (pp. 67-73). Washington, DC: American Psychological Association.

Schumann, D. W., \& Thorson, E. (1987). The influence of viewing context on commercial effectiveness: A selection-processing model. Paper presented at Division 23 of the American Psychological Association Annual Meeting, New York, August.

Schumann, D. W., \& Thorson, E. (1990). The influence of viewing context on commercial effectiveness: a selection processing model. In J. H. Leigh \& C. R. Martin (Eds.), Current Issues and Research in Advertising, 12(1), 1-24.

Schwerin, H. S. (1958). Do today's programs provide the wrong commercial climate? Television Magazine, 15(8), 44-47, 90-91.

Smith, D. C. (1956). Television program selection, liking for television programs, and levels of attention given to television by housewives. Radio-Television Audience Studies, 23, Department of Speech, Ohio State University.

Soldow, G. F., \& Principe, V. (1981). Response to commercials as a function of program context. Journal of Advertising Research, 21(2), 59-65.

Television Audience Assessment, Inc. (1984). Program impact and program appeal: Qualitative ratings and commercial effectiveness. In-house paper, Boston, MA.

Thorson, E., Friestad, M., \& Zhao, X. (1987). Attention to program context in a natural viewing environment: Effects on memory and attitudes toward commercials. Paper presented at the Association for Consumer Research, Boston, October.

Thorson, E., \& Oberman, H. (1985). Commercial complexity and local and global involvement in programs: Effects on viewer response. Paper presented at the Association for Education in Journalism and Mass Communication, Memphis, TN, August.

Thorson, E., \& Reeves, B. (1986). Effects of over-time measures of viewer liking and activity during programs and commercials on memory for commercials. In R. Lutz, (Ed.), Advances in Consumer Research, 13. Provo, UT: Association for Consumer Research.

Thorson, E., Reeves, B., \& Schleuder, J. (1985). Message complexity and attention to television. Communication Research, 12(4), 427-454.

Thorson, E., Reeves, B., Schleuder, J., Lang, A., \& Rothschild, M. L. (1985). Effects of program context on the processing of television commercials. In N. Stephens, (Ed.), 
Proceedings of the 1985 conference of American Academy of Advertising (R58-R63). Tempe, AZ: College of Business, Arizona State University.

Twyman, W. A. (1974). Setting TV advertising in context: Research Bureau limited. In-house paper, London.

Yi, Y. (1990). Cognitive and affective priming effects of the context for print advertisements. Journal of Advertising, 19(2), 40-48. 